\title{
Plasmacytoma of the thyroid
}

\author{
J. R. S. MORE, D. W. DAW SON, A. J. RALSTON, AND ISLA CRAIG \\ From the Department of Pathology, University of Manchester, the Department of \\ Pathology, Crumpsall Hospital, Manchester, the Department of Medicine, Royal \\ Lancaster Infirmary, Lancaster, and the Department of Pathology, Selly Oak \\ Hospital, Birmingham
}

SYNOPSIS Three cases of plasmacytoma of the thyroid are described and their clinical and histological features recorded. Two were considered to be true extramedullary plasmacytomas, the third the initial manifestation of a disseminated myelomatous process. Plasmacytomas of the thyroid are shown to have many features in common with malignant lymphomas in this site, including an association with Hashimoto thyroiditis in more than half the reported cases. No certain method of assessing the prognosis in any individual case has yet been described.

Extramedullary plasmacytoma is the least common form of plasma cell tumour. The tumours may be solitary or multiple and occur most frequently in the upper respiratory tract, half of Hellwig's (1943) series of 128 cases originating there. The next most common site is the conjunctiva. Reports of tumours occurring elsewhere are largely confined to single cases. The thyroid is one of the rarer sites of extramedullary plasmacytoma, Guerrier, Mirouze, Pages, Jaffiol, and Dejean (1963) recording the sixth case. Three further cases are reported here, including one briefly mentioned elsewhere (Todd, 1965).

\section{CASE REPORTS}

CASE 1 A 51-year-old woman was seen at the Manchester Victoria Memorial Jewish Hospital in December 1966 with a three months' history of a lump in the neck of increasing size. She experienced some dysphagia. There were no toxic symptoms. Examination showed a firm but not hard enlargement of the thyroid just to the left of the isthmus. There was no cervical lymphadenopathy. The haemoglobin was $13.5 \mathrm{~g}$ per $100 \mathrm{ml}$, and the white cell count 6,500 per cubic millimetre with a normal differential. At operation on 9 December an 'adenoma' of the isthmus was removed together with part of the left lobe of the thyroid which showed some nodular enlargement. Skeletal survey, bone marrow examination, and serum protein electrophoresis were all normal. Serum proteins were $7.2 \mathrm{~g}$ per $100 \mathrm{ml}$, with no increase in the globulin fraction. In January 1967 the patient was readmitted and a total thyroidectomy performed. Postoperative recovery was uneventful and the patient was maintained on L-thyroxine $\mathbf{0 . 2} \mathrm{mg}$ daily. At the time of

Received for publication 7 March 1968. writing all investigations have remained negative and there is no evidence of recurrence.

Pathological findings The partial thyroidectomy specimen consisted of a nodular mass of thyroid weighing $15 \mathrm{~g}$ and measuring $4 \times 3 \times 1.5 \mathrm{~cm}$. In one part there was a lobulated, rather ill defined swelling, $2 \mathrm{~cm}$ in maximum diameter, of soft consistency and yellow-white colour, which appeared to infiltrate into the adjacent white tissue. No capsule could be clearly defined.

Histologically the thyroid was somewhat nodular and in most areas showed active thyroiditis with an interstitial infiltrate composed mainly of lymphocytes with occasional germinal centres. Some acini contained dark eosinophilic colloid and were lined by cuboidal cells whilst others were hyperplastic with columnar epithelium, finely granular cytoplasm, and pale scalloped colloid. Foci of Askanazy cell change occurred, and intraacinar clusters of macrophages, lymphocytes, and plasma cells were also present. Some acini were distorted, compressed, and represented only by a cluster of closely grouped pale vesicular nuclei with little cytoplasm (Fig. 1).

In the lobulated area a plasmacytoma was present. The distorted acini were surrounded and separated by a diffuse, sheet-like infiltrate of quite large round or oval cells with eccentric nuclei (Fig. 2), often showing chromatin clumps radially arranged round the nuclear membrane in 'cart wheel' fashion. Some cells had a paranuclear clear zone. The cytoplasm was basophilic and sometimes difficult to define on haematoxylin and eosin staining; it was better seen with methyl green-pyronin stains.

Many of the infiltrating cells were larger and resembled small reticulum cells, though most of these too showed pyroninophilia. Considerable numbers of cells in mitosis were present. Occasional large vesicular nuclei with scanty, pale cytoplasm occurring in the background of the plasma cell infiltrate were considered to be residual parenchymal cells rather than reticulum cells. Reticulin 


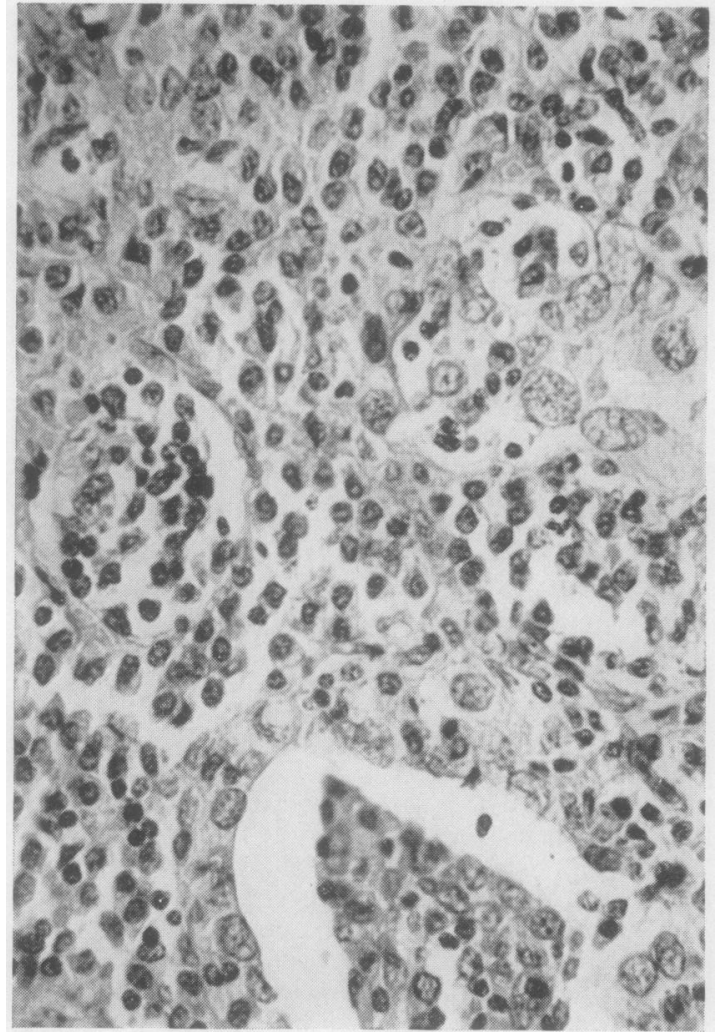

FIG. 1 .

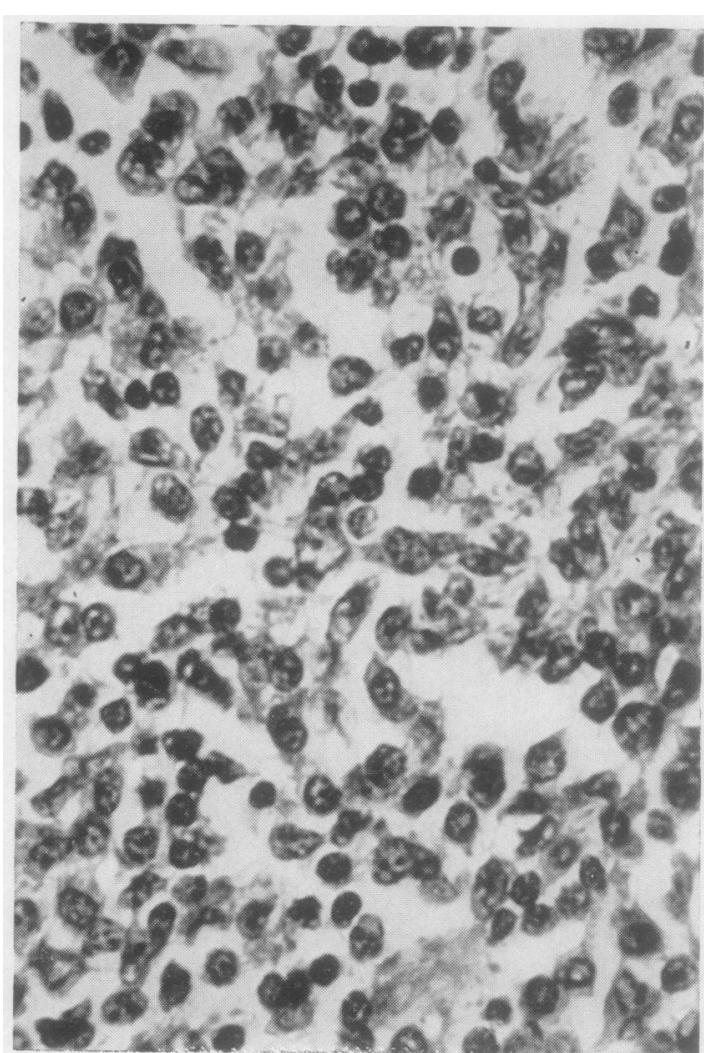

FIG. 2.

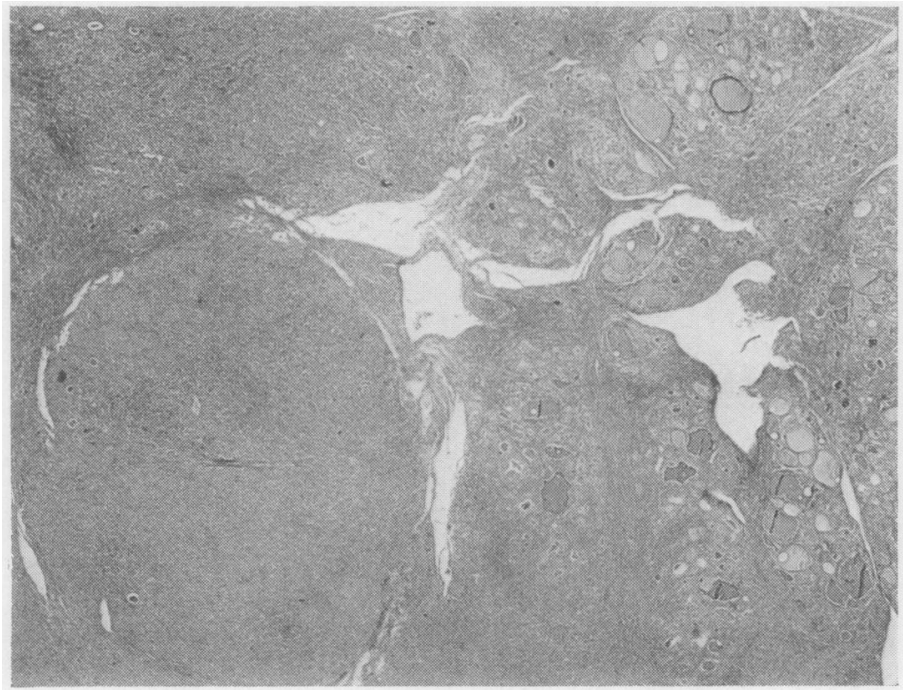

FIG. 1. Case 1. Damaged acini containing macrophages and plasma cells and acinar remnants with interstitial plasma cell infiltrate. $\times 450$.

FIG. 2. Case 1. Neoplastic infiltrate of plasma cells and plasmablasts. $\times 700$.

FIG. 3. Case 1. Nodular thyroid with interstitial neoplastic plasma cell infiltrate. Solid nodule is composed solely of plasma cells. $\times 20$.

FIG. 3 . 
staining showed a fine meshwork surrounding clusters of infiltrating cells and a vague follicular pattern was seen in some areas. In places amongst the plasma cell sheets residual follicular lymphoid aggregates with germinal centres occurred. The tumour was not unduly vascular and there was no special relationship between tumour cells and blood vessels. Some nodules were composed exclusively of plasma cells (Fig. 3). Infiltration reached to, but did not clearly penetrate, the thyroid capsule.

The total thyroidectomy specimen consisted of both lobes, each of which measured $5 \times 2.5 \times 1 \mathrm{~cm}$, and was of firm consistency. Histological examination showed only chronic thyroiditis with a mainly lymphocytic interstitial infiltrate and a foreign body giant cell reaction to the suture material used at the initial operation. There was no evidence of residual plasmacytoma.

CASE 2 A 44-year-old woman was seen at the Manchester Royal Infirmary in October 1964 with a 10-year history of swelling in the neck increasing in size during the last three months and producing occasional dysphagia. There were no toxic symptoms. Examination showed a massive, diffusely nodular, painless enlargement of both lobes of the thyroid. The haemoglobin was $13.4 \mathrm{~g}$ per $100 \mathrm{ml}$, the white cell count 6,000 per cubic millimetre, with a normal differential, and the ESR was $35 \mathrm{~mm}$ per hour. Radiographs of the thoracic inlet showed some tracheal deviation and compression. At operation on 26 October there was some retrosternal prolongation of the thyroid. A subtotal thyroidectomy was performed, the thyroid proving difficult to dissect posteriorly and very friable. Skeletal survey, bone marrow examination, and serum protein electrophoresis were all normal. Serum proteins were $7.7 \mathrm{~g}$ per $100 \mathrm{ml}$, and the albumin/globulin ratio was $1 \cdot 65$. No antibodies were detected by thyroid autoprecipitin, complement-fixation, or tanned red cell agglutination tests. There was no proteinuria. She made an uneventful postoperative recovery. On review in February 1965 she was found to have myxoedema, corrected by L-thyroxine $\mathbf{0 . 3} \mathrm{mg}$ daily. In September she gave a history of two weeks' swelling of the right side of the neck, found to be due to an enlarged lymph node $3 \mathrm{~cm}$ in diameter below the angle of the jaw. There was also a small nodular recurrence in the left lobe of the thyroid. Repeated marrow examination and serum protein electrophoresis were still normal. She was given a course of radiotherapy in October and both recurrence and lymph node then disappeared. When last seen in December 1967 she was still well with no evidence of recurrence.

Pathological findings The specimen consisted of two large, oval masses of equal size, each weighing $180 \mathrm{~g}$. The surface was covered by a thin, smooth capsule, incomplete over considerable areas. Loosely attached to one lobe were several separate nodules, apparently enlarged lymph nodes. The cut surface throughout had a lobulated, pale grey, fleshy appearance and was soft. The nodes appeared similar.

All sections showed plasmacytoma. Between the few remaining thyroid acini were sheets of small, round or oval plasma cells (Fig. 4). Occasional binucleate forms occurred. Numbers of larger cells with a more open

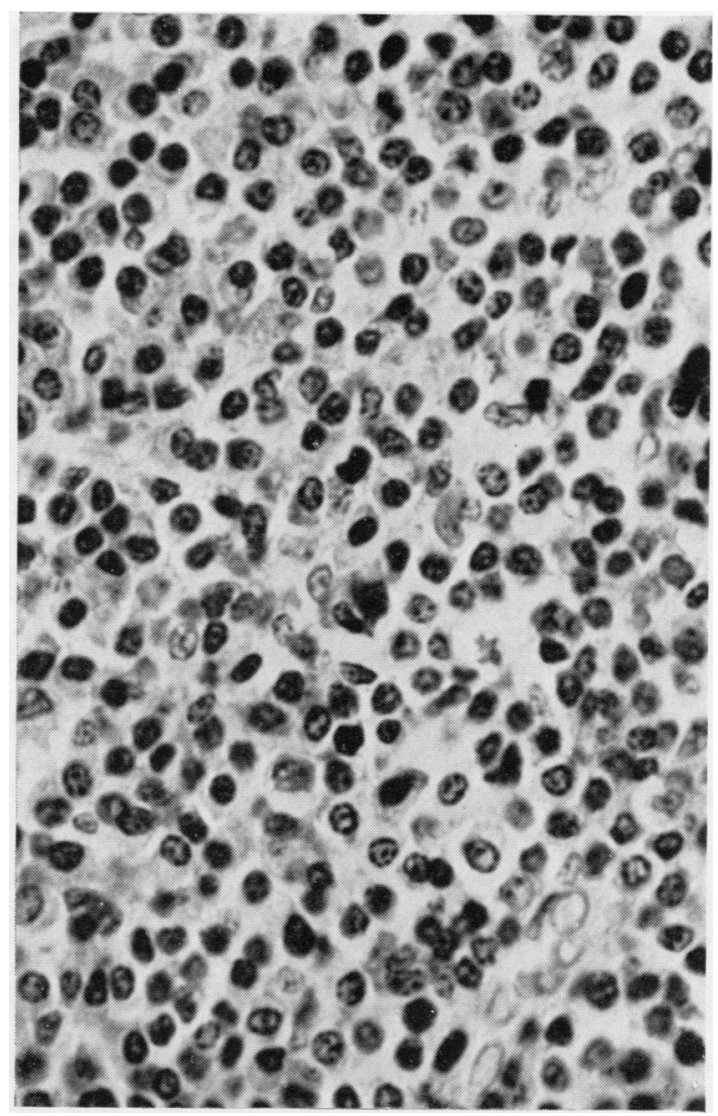

FIG. 4. Case 2. Infiltrate of mainly mature plasma cells. $\times 700$.

nucleus, probably plasmablasts, were also present. Mitotic figures were infrequent. Cells with large vesicular nuclei and scanty cytoplasm occurring in the background were probably incompletely obliterated parenchymal cells. A fine reticulin framework was seen round small groups of plasma cells. The tumour was not particularly vascular and no relationship existed between capillaries and plasma cells. The infiltrate extended through the capsule in places.

As in case 1 the surviving thyroid tissue showed chronic thyroiditis. A few clusters of lymphocytes, occasionally with germinal centres, persisted, particularly around damaged acini. Askanazy cell change was prominent and intraacinar macrophages and plasma cells were present. No wholly tumour-free thyroid was found but in the least involved area there was still evidence of thyroiditis.

The lymph nodes also showed diffuse plasma cell infiltration with capsular invasion. In some areas a little normal architecture was preserved with occasional lymphoid aggregates and a few surviving sinus histiocytes.

CASE 3 A 50-year-old man was seen at the Manchester 
Royal Infirmary in August 1954 with a year's history of progressive swelling of the left side of the neck. Two months earlier enlarged lymph nodes had developed in the left posterior triangle of the neck. There were no toxic symptoms. Examination showed a firm tumour mass enlarging the left lobe of the thyroid, and several enlarged, soft, mobile nodes. A chest radiograph confirmed marked left lobe enlargement with tracheal compression and displacement to the right. Biopsy from one of the enlarged cervical nodes showed infiltration by a tumour composed of small cells with eosinophilic cytoplasm, reported as a small-cell thyroid carcinoma. A course of radical radiotherapy was given and completed in October 1954, and the thyroid tumour and nodes became impalpable. Left supraclavicular node enlargement in September 1955 necessitated further radiotherapy. Myxoedema developed in March 1956 and was controlled by 2 grains of thyroid extract daily. In September, the left supraclavicular node which had enlarged again was excised and the diagnosis of 'plasmacytoma of thyroid with involvement of regional nodes' was now made. Haemoglobin was $14.8 \mathrm{~g}$ per $100 \mathrm{ml}$, and the white cell count 5,000 per cubic millimetre with a normal differential. A skeletal survey was normal. The patient remained well until May 1957 when the face and left arm became swollen, due to the presence of a large mediastinal gland mass. Irradiation produced symptomatic relief. One month later, the left inguinal glands and left testis enlarged. The groin was irradiated and the testis excised. As this also showed plasmacytoma, it was now thought that this was a generalized process with tumours localizing in various regions. Marrow biopsy yielded little material; the predominant cell, however, was an atypical plasma cell. Serum proteins were $8.5 \mathrm{~g}$ per $100 \mathrm{ml}$ with an albumin/globulin ratio of 0.85 ; electrophoresis showed an increase in the gamma fraction. Bence-Jones protein was not detected. In January 1958 a left parotid swelling was irradiated; this was followed by repeated irradiation of nodes in the left groin. In April there was generalized enlargement of lymph nodes in the lower trunk which were again irradiated. The haemoglobin was now $5.2 \mathrm{~g}$ per $100 \mathrm{ml}$ and the albumin/globulin ratio had fallen to 0.65 through a further rise in gamma globulin. Death occurred on 13 May 1958. A post-mortem examination performed by Dr M. Levene showed widespread neoplasm with tumour deposits in the right axilla; in the psoas muscle in the left iliac fossa extending up to surround the left kidney; in the left leg replacing the gastrocnemius and popliteal muscles and infiltrating the patella and lower end of the femur; and in the right testis. Sections of the marrow from various sites appeared macroscopically normal.

Histological findings The initial lymph node biopsy showed numbers of round or oval pyroninophil plasma cells in the peripheral sinuses. Extending from there a diffuse sheet-like infiltrate replaced more than half the normal nodal tissue; at its periphery plasma cells infiltrated amongst the littoral histiocytes. In the centre of the inflitrate there was considerable pleomorphism with many reticulum cells with large vesicular nuclei and prominent nucleoli (Fig. 5). Occasional binucleate forms occurred. Mitotic figures were numerous in the centre of the infiltrate. Giant plasma cells were present and cells

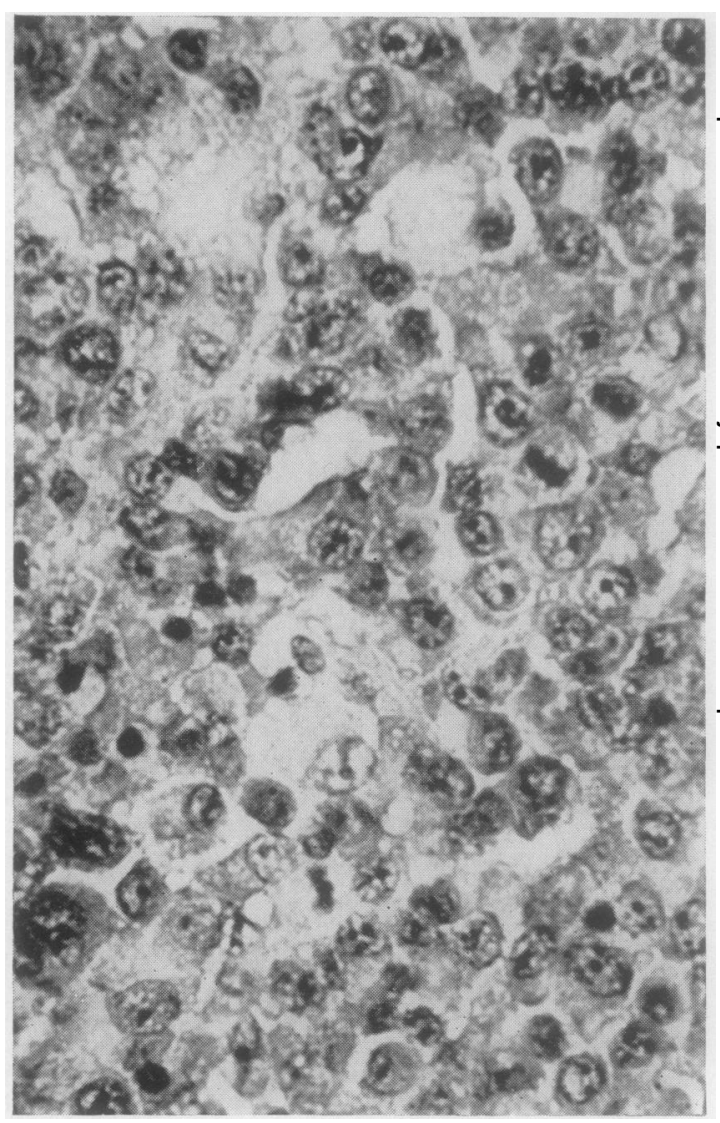

FIG. 5. Case 3. Area of reticulum cells. Original lymph node biopsy. $\times 700$.

with nuclei intermediate between mature plasma cells and reticulum cells; these appeared to be plasmablasts. A fine reticulin network was seen between small clusters 3 of these atypical plasma cells.

The second node biopsy also showed a plasma cell $\stackrel{\circ}{3}$ infiltrate with capsular invasion. The plasma cells were of

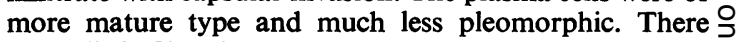
was a little fibrosis.

Section of testis showed a plasma cell deposit separating, 을 replacing, and infiltrating between testicular tubules in typical lymphomatous fashion (Fig. 6). Pleomorphism $\sigma$ was not as marked as in the original node biopsy, though $\mathrm{N}$ mitoses were quite frequent. The tubules surrounding the tumour were compressed and rather atrophic. Sections of $\omega$ this biopsy were submitted to the Testicular Tumour Registry. It was included as case 3 of their series of 0 plasma cell tumours (Gowing, 1964).

The necropsy material showed pleomorphic plasma $\stackrel{\infty}{+}$ cell infiltrate in all deposits. The bone marrow showed an 7 increase in plasma cells. The thyroid was densely fibrotic $\bar{O}$ and poorly cellular. A very occasional acinus showing $\overrightarrow{\mathbb{D}}$ Askanazy cell change remained, surrounded by clusters $\frac{\rho}{\mathbb{D}}$ of lymphocytes and an occasional typical plasma cell. 


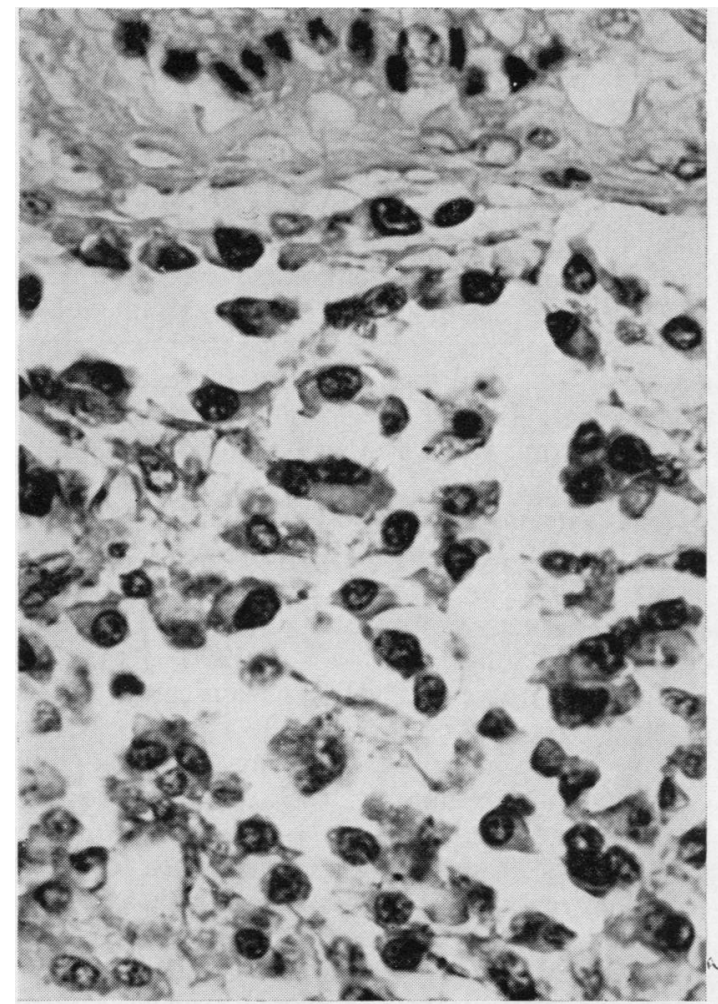

FIG. 6. Case 3. Large cells with typical plasma cell configuration infiltrating between testicular tubules. $\times 700$.

A few larger blood vessels showed considerable hyaline thickening of their walls. Irregular patchy fibrosis extending into the perithyroid fat suggested that this might be the end stage of an extracapsular plasma cell infiltration destroyed by irrradiation. There was no residual plasma cell tumour.

\section{DISCUSSION}

The predominant cell in each of our cases is a plasma cell with the typical features described by Marschalkó (1895). The most convincing histogenetic theory of origin of myeloma cells is that envisaging them as abnormal derivatives of primitive reticular cells, the stem cell of lymphocyte production (Evans, 1966), so that plasma cell tumours may be classified as reticuloses. Certainly their pattern of infiltration as exemplified in the testis in case 3 and in the thyroid supports this, as it is identical with that of malignant lymphomas. The close histogenetic and functional relationship of reticulum cells, lymphocytes, and plasma cells is shown by the difficulty of classifying lymphoid tissue tumours and distinguishing various lymphomas from certain myelomas.

In case 1 difficulty was encountered in deciding the nature of the neoplastic cells as they showed features of plasmacytoma, reticulum cell sarcoma, and even follicular lymphoma (Sclare, 1966). However, many of the cells which resembled small reticulum cells of the type seen, for example, in Hodgkin's disease, although apparently lacking cytoplasm on haematoxylin and eosin staining, had ample pyroninophil cytoplasm on Unna-Pappenheim staining, suggesting that they, too, belonged to the plasma cell series. Cox's (1964) case 5 of malignant thyroid lymphoma also had a mixed picture with reticulum cells, lymphoblasts, and large abnormal cells, many with features intermediate between reticulum and myeloma cells. The vague follicular pattern in some areas, accentuated by reticulin stains and best seen in case 1 , is insufficient to justify a diagnosis of follicular lymphoma, since other reticuloses can be follicular. Case 3 showed cellular polymorphism with many reticulum cells in the initial biopsy. Where the typical nuclear pattern is largely lacking and the cytoplasm scanty, confusion between plasmacytoma and reticulum cell sarcoma is likely. Alternatively misdiagnosis as small cell anaplastic thyroid carcinoma can occur, as initially in case 3 . This is not surprising as only comparatively recently has malignant lymphoma of the thyroid been unequivocally accepted as an entity (Cox, 1964).

In none of our cases was any support found for Voegt's (1938) suggestion that the plasma cells might arise by budding from the tumour capillary endothelium.

It is clear that different pathological conditions have been described as 'plasmacytomas' owing to the difficulty of determining whether individual tumours are neoplastic or inflammatory. In our cases, the combination of invasion and actual replacement of thyroid parenchyma clearly establishes the neoplastic nature of the process (Sclare, 1966). The lymph node involvement, the increased mitotic activity, and the rather pleomorphic nature of the infiltrates further support this view.

Ackerman (1964) makes the point that the mere presence of large numbers of plasma cells should not lead to the diagnosis of a plasma cell neoplasm but indicates that granulomas may become large enough to be mistaken for true tumours. In such cases, an infiltrate consisting predominantly of plasma cells is found with an admixture of lymphocytes or polymorphs, occasionally macrophages and even fibroblasts. Vascular proliferation is common and mitotic figures may also be seen. From their study of extramedullary plasmacytomas, Dolin and Dewar (1956) excluded plasmacytomas of the conjunctiva 
discussed by Hellwig (1943), as they, in company with others, considered them to be inflammatory granulomas and not true neoplasms. The case of thyroid plasmacytoma reported by May, André, and Caine (1950) clearly would be more appropriately termed 'plasma cell granuloma'. Here thyroid enlargement due to predominantly plasma cell infiltration was described in association with chronic thyroiditis; the authors themselves considered the process benign. Brewer and Orr (1953) re-examined 22 thyroid tumours where an initial diagnosis of undifferentiated carcinoma had been made. Two of these cases showed plasma cells in large numbers (group 1). Case 1 was a 67-year-old woman with a goitre 'the size of a hen's egg' which she had noticed for a year. At partial thyroidectomy a large nodule was removed from the region of the isthmus. Sections showed extensive loss of thyroid parenchyma and replacement by numerous closely set round cells, mostly plasma cells. No further description of the infiltrate is given. The authors accepted this as evidence that the basic condition was probably thyroiditis, a suggestion supported by the Hürthle cell change in the few surviving acini. This was probably a plasma cell granuloma, the follow-up for four and a half years also favouring their view that the process was benign. Ackerman (1964) claims to have seen several examples of simple plasma cell infiltration of the thyroid and instances a case of a 41-year-old woman with tumour-like involvement of the thyroid, which weighed $300 \mathrm{~g}$ at resection. He states that follow-up supports his opinion that the changes were probably non-neoplastic. Unfortunately no details of the microscopical findings are given.

Cases of multiple myeloma commencing in a solitary form are also termed plasmacytoma. Hayes, Bennett, and Heck, (1952) claimed that $71 \%$ of multiple myelomas had extramedullary involvement and a solitary extramedullary tumour may be the initial mode of presentation (Dolin and Dewar, 1956). Our third case is difficult to classify but is probably an unusual variant of disseminated myeloma-shown by the raised serum gamma globulin and increase in marrow plasma cells. Extramedullary plasmacytomas do not show manifestations of disturbance of protein metabolism (Dolin and Dewar, 1956). There is no direct, but considerable indirect, evidence that case 3 is a thyroid plasmacytoma. The initial swelling was in the thyroid and its related cervical nodes, confirmed radiologically where the left lobe enlargement was seen, accompanied by tracheal compression and displacement. After irradiation both thyroid and nodes became impalpable. Confirmation of effective thyroid destruction was provided by the development of myxoedema within a few months and the post-mortem thyroid fibrosis. Guerrier et al (1963) reported a 54-year-old woman who presented with a thyroid tumour; immunoelectrophoresis later revealed a BenceJones type paraprotein. Marrow examinations and a skeletal survey were negative but the case had only been followed for a year. Frequently dissemination takes longer than this to occur, especially in cases initially presenting as a soft tissue mass. As Bichel and Kirketerp (1938) assert, the term extramedullary $\overrightarrow{0}$

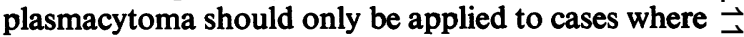
disseminated myelomatosis can be excluded by radiological, haematological, and chemical means, $\vec{\Omega}$ to which Dolin and Dewar (1956) add follow-up for at least two years.

True extramedullary plasmacytomas, of which if cases 1 and 2 are examples, can vary considerably $\stackrel{\circ}{\rightarrow}$ in size. They are usually well-defined, firm and spherical but may be lobulated or polypoid and show evidence of infiltration. Histologically, they are $\vec{\sim}$ composed almost exclusively of plasma cells, arranged $\mathbb{D}$ in sheets or clusters with a delicate, supportive $\mathbb{D}$ stroma which may be vascular. The distinctive $\frac{3}{6}$ characteristics are not always clearly delineated and $\stackrel{\mathbb{\perp}}{\rightarrow}$ considerable cellular atypia and variation in size $\vec{\theta}$ may be seen. Mitoses are often numerous. In cases $1 \stackrel{\circ}{\circ}$ and 2 marrow and electrophoretic studies have been consistently negative. Case 2 supports the observation of Dolin and Dewar (1956) that lymph node involvement is almost the rule in extramedullary plasmacytoma, though exceedingly rare in multiple myeloma. Tumour recurrence in this case could have been expected as surgical removal was incomplete, This is a typical clinical behaviour pattern (Dolin and Dewar, 1956).

In the thyroid extramedullary plasmacytoma is rare, Hazard and Schildecker (1949) finding only two cases in over 14,000 thyroid operations. The reports show that they occur predominantly in women; the usual age range is 50 to 70 . Thyroid enlargement is nodular or diffuse and painless; either or both sides may be affected, and there are no symptoms of toxicity. Capsular infiltration and cervical lymphadenopathy may occur. The tumours are usually considered to be true neoplasms though Shaw and Smith (1940) thought theirs a type of $\sigma$ plasma cell hyperplasia. Primary reticuloses of the $N$ thyroid can be difficult to distinguish from extreme examples of chronic thyroiditis, but in our cases, $\omega$ as we have stated, the invasion and replacement of thyroid parenchyma clearly show the neoplastic nature of the condition.

The present plasmacytomas have arisen in glands already affected by chronic thyroiditis, $\frac{0}{0}$ regardless of whether there was (case 2) or was not $\underset{\mathbb{D}}{ }$ (case 1) a history of preceding thyroid disease. 
The surviving parenchyma shows most of the histological features of Hashimoto thyroiditis which do not occur in response to neoplasm alone. Thyroiditis was also present in the 50-year-old woman reported by Shaw and Smith (1940). We have reviewed the sections by courtesy of Dr D. N. Hutchinson of Preston and consider the lesion to be a true extramedullary plasmacytoma. The pattern of thyroiditis is similar to that of our present cases and is of Hashimoto rather than Riedel type. Hazard and Schildecker's (1949) second case, a man of 71, was also described as having evidence of preceding thyroiditis. Barton and Farmer (1950) specifically disclaim it in their patient. In Voegt's (1938) case, there is no description of tumour-free parenchyma making assessment of previous thyroiditis impossible. Malignant lymphoma of the thyroid is frequently associated with inflammatory lymphoid infiltration or hyperplasia, and in some cases the lymphoid tissue is an integral part of Hashimoto thyroiditis, as in case 5 of Cox (1964). The proportion of cases with an associated thyroiditis varies considerably in the reports of different authors, the average being a third. Of the six cases of lymphosarcoma of Metcalfe and Sclare (1961), three arose in diffuse chronic thyroiditis. This, however, does not necessarily imply an aetiological association. Cox (1964) suggested that such a relationship might exist; she thought that in her cases 1 and 6 the neoplastic cells arose from lymphoid tissue already present as part of thyroiditis. As the plasma cell is derived from reticulum cells and is also a feature of Hashimoto thyroiditis, so plasmacytoma could arise in like manner.

The prognosis of thyroid plasmacytoma is difficult to establish as few cases have been followed up for long, the longest recorded being the first case of Hazard and Schildecker (1949), where the patient died six years after irradiation of a recurrence arising 10 years after the original lobectomy and irradiation. The cause of death was undetermined. The patient of Shaw and Smith (1940) died in 1961 from acute pyelonephritis. She had been treated by total thyroidectomy followed by irradiation for diffuse thickening in the scar. At necropsy there was no evidence of neoplasm and in the intervening 23 years there had been no recurrence. Hellwig (1943) showed, particularly among nasopharyngeal plasmacytomas, that after surgical removal or irradiation, recurrence or dissemination was not inevitable, quoting cases wholly tumour free $10 \frac{1}{2}$ to 18 years later. Unfortunately cytological appearances did not prove to be of much value in assessing the prognosis in individual cases. He classified nasopharyngeal growths into non-cancerous, single and multiple, and cancerous, with and without metastases, taking local invasion as the basis of separation. His histological descriptions show that typical plasma cell tumours occurred in each group and some of the 'non-cancerous' tumours recurred. Cells with two, three, or more nuclei were not uncommon in noncancerous cases and large numbers of mitoses were not an indication of malignancy. Generally however, more pleomorphic tumours behaved more aggressively and our observations support this pattern because the most pleomorphic tumour in our series (case 3) behaved very aggressively.

It may be that Innes and Newall's (1961) simple hypothesis that solitary and multiple myeloma, diffuse myelomatosis, and extramedullary plasmacytoma are merely differing aspects of a single pathological process is correct, but the occasional plasmacytomas with long recurrence-free survival do suggest the possibility that some tumours are genuinely solitary, arising as a local disturbance of extramedullary reticulum cells, and are not forerunners of a generalized process. Todd's (1965) report of a $60 \%$ five-year survival in irradiated solitary plasmacytoma as opposed to $6 \%$ in irradiated multiple myeloma amply justifies energetic treatment of these local conditions. Unfortunately, as yet there appears to be no certain method of distinguishing those which will respond from those which disseminate.

We are indebted to Professor A. C. P. Campbell and Dr O. G. Dodge for much helpful criticism; to Mr G. Humberstone for the photomicrographs; to Misses C. Abbott, M. Horsfall, and G. Wildgoose for the histological preparations, and to Miss L. Partington for secretarial assistance.

\section{REFERENCES}

Ackerman, L. Y. (1964). Surgical Pathology, 3rd ed., pp. 923, 356. Mosby, St. Louis.

Barton, F. E., and Farmer, D. A. (1950). Ann. Surg., 132, 304.

Bichel, J., and Kirketerp, P. (1938). Acta radiol. (Stockh.), 19, 487.

Brewer, D. B., and Orr, J. W. (1953). J. Path. Bact., 65, 193.

Cox, M. T. (1964). J. clin. Path., 17, 591.

Dolin, S., and Dewar, J. P. (1956). Amer. J. Path., 32, 83.

Evans, R. W. (1966). Histological Appearances of Tumours, 2nd ed., pp. 225, 230. Livingstone, Edinburgh.

Gowing, N. F. C. (1964). In Pathology of Testicular Tumours, p. 93, edited by D. H. Collins and R. C. B. Pugh. Livingstone, Edinburgh.

Guerrier, Y., Mirouze, J., Pages, A., Jaffiol, C., and Dejean, Y. (1963). Ann. Endocr., 24, 637.

Hayes, D. W., Bennett, W. A., and Heck, F. J. (1952). Arch. Path., 53, 262.

Hazard, J. B., and Schildecker, W. W. (1949). Amer. J. Path., 25, 819. Hellwig, C. A. (1943). Arch. Path., 36, 95.

Innes, J., and Newall, J. (1961). Lancet, 1, 239.

Marschalkó, T.v. (1895). Arch. Derm. Syph., 30, 241.

May, E., André, M. J., and Caine. (1950). Ann. Oto-laryng., 67, 826.

Metcalfe, W. J., and Sclare, G. (1961). Brit. J. Surg., 48, 541.

Sclare, G. (1966). Personal communication.

Shaw, R. C., and Smith, F. B. (1940). Arch. Surg., 40, 646.

Todd, I. D. H., (1965). Clin. Radiol., 16, 395.

Voegt, H., (1938). Virchows Arch. path. Anat., 302, 497. 